\title{
Follow up of precocious pseudopuberty associated with isolated ovarian follicular cysts
}

\author{
K A Rodriguez-Macias, E Thibaud, M Houang, C Duflos, C Beldjord, R Rappaport
}

\begin{abstract}
The clinical outcomes of seven girls presenting with pseudosexual precocity caused by isolated autonomous ovarian follicular cysts are presented. Six of the seven girls, aged 11 months to 6.9 years, had a unilateral ovarian cyst detected by ultrasound at the first acute episode. Plasma oestradiol was raised in only five of the cases, but all had a low response to luteinising hormone releasing hormone stimulation. Follow up lasted for up to eight years with recurrent episodes of variable frequency and severity in all seven patients. Evidence of McCuneAlbright syndrome appeared later in only three patients. It could not be predicted from the initial symptoms or the clinical course. Mutations of the $G_{s} \alpha$ protein leading to activation were investigated in the lymphocytes and ovarian and bone tissues of four patients. Only one patient showed a mutation in bone tissue. Close follow up with repeated searches for skeletal lesions remains necessary since the distribution of somatic mutations cannot be assessed by molecular studies. Most patients with recurrent ovarian cysts require a conservative approach.

(Arch Dis Child 1999;81:53-56)
\end{abstract}

Endocrinology Unit, Hôpital des Enfants Malades, 149 rue de Sèvres, 75015 Paris, France

K A Rodriguez-Macias

E Thibaud

M Houang

C Duflos

R Rappaport

Biochemistry and Molecular Genetic Laboratory, Hôpital Cochin, Paris, France

C Beldjord

Correspondence to:

Dr Thibaud.

Accepted 8 December 1998

Keywords: pseudopuberty; ovarian follicular cyst; G protein mutation

Acute episodes of early vaginal bleeding with breast development is an unusual onset of sexual precocity in prepubertal girls. ${ }^{1}$ Initially described by Benedict, ${ }^{2}$ some of these patients may later develop McCune-Albright syndrome. Several reports have shown that it is caused by autonomous ovarian activation, occasionally with a large ovarian cyst detected by ultrasound. ${ }^{3-6}$ However, the clinical course of this condition before puberty has not been completely described. ${ }^{7}$ This study therefore provides clinical guidelines for the diagnosis and follow up of these patients, who often suf-

Table 1 Acute ovarian follicular cyst before age of puberty: clinical presentation at diagnosis

\begin{tabular}{llllll}
\hline Case & $\begin{array}{l}\text { Chronological age } \\
\text { (years) }\end{array}$ & $\begin{array}{l}\text { Bone age } \\
\text { (years) }\end{array}$ & $\begin{array}{l}\text { Vaginal } \\
\text { bleeding }\end{array}$ & $\begin{array}{l}\text { Pubertal Tanner } \\
\text { stage }\end{array}$ & Growth rate \\
\hline 1 & 6.9 & 5.9 & + & B3 P2 & Increased \\
$2^{\star}$ & 1.6 & 2.0 & + & B2 P1 & Normal \\
3 & 5.9 & 6.0 & + & B3 P1 & Increased \\
4 & 2.2 & 2.0 & 0 & B2 P2 & Normal \\
5 & 5.4 & 5.3 & + & B2 P1 & Increased \\
$6^{\star}$ & 0.9 & 1.3 & + & B2 P2 & Increased \\
$7^{\star}$ & 2.6 & 2.6 & + & B2 P3 & Increased \\
\hline
\end{tabular}

${ }^{\star}$ Clinical evidence of McCune-Albright syndrome during follow up. fer from repeated episodes of vaginal bleeding, acute oestrogenisation, and follicular cysts. This clinical picture appears to be quite characteristic within the scope of isosexual precocity in girls. Autonomous ovarian activation was suggested in one of our patients by the finding of a $G$ protein mutation that segregates with the McCune-Albright syndrome. ${ }^{8}$

\section{Patients and methods}

PATIENTS AND HORMONE MEASUREMENTS

Seven girls aged 11 months to 6.9 years (mean age 3.6 years) were referred to us for sexual precocity with recent signs of oestrogenic activity (vaginal bleeding and breast development). Some of them had pubic hair (table 1). Their pubertal stages were determined according to Tanner, ${ }^{9}$ and McCune-Albright type skin pigmentation was looked for. Linear growth was monitored according to the Centre International de l'Enfance curves, ${ }^{10}$ and bone age was measured according to Greulich and Pyle. ${ }^{11}$ They all underwent a pelvic ultrasound examination at the time of their initial referral to assess ovarian structure and uterus size and morphology according to reference prepubertal data. ${ }^{12}$ The sizes of cysts are given as their largest diameter. Each patient underwent a complete skeletal radiographic examination. Plasma oestradiol, luteinising hormone $(\mathrm{LH})$, follicle stimulating hormone (FSH), dehydroepiandrosterone sulfate, thyroid stimulating hormone, thyroxine, and prolactin were measured. ${ }^{13} 14$ The luteinising hormone releasing hormone (LHRH) stimulation test was used to evaluate $\mathrm{LH}$ and FSH responsiveness, and was repeated in some patients 15 months to six and a half years later. The mean (range) prepubertal control values of plasma basal and peak responses to LHRH in our laboratory are from $0.99(<0.2-2.2)$ to $3.0(1.5-4.5) \mathrm{mIU} / \mathrm{ml}$ for LH, and from $1.9(0.5-4.0)$ to 13.2 (4.0-22.0) $\mathrm{mIU} / \mathrm{ml}$ for FSH.

\section{MUTATION IDENTIFICATION}

Genomic DNA was extracted from peripheral blood leucocytes, tissue specimens (bone, ovary), or both, obtained at surgery by standard methods. The method was slightly modified for bone fragments to include digestion with proteinase $\mathrm{K}(2 \mathrm{mg} / \mathrm{ml}, 3 \times 3$ hours $)$.

\section{POLYMERASE CHAIN REACTION AND}

DENATURATING GRADIENT GEL ELECTROPHORESIS CONDITIONS AND SEQUENCING

The domains containing exons 8 and 9 were investigated by the polymerase chain reaction (PCR) using appropriate primers (details not shown). Reactions were performed in a volume 
of $100 \mu \mathrm{l}$ containing $67 \mathrm{mM}$ Tris- $\mathrm{HCl}(\mathrm{pH}$ 8.8), $16.6 \mathrm{mM} \mathrm{SO}\left(\mathrm{NH}_{4}\right), 2.5 \mathrm{mM} \mathrm{MgCl}_{2}$, $10 \mathrm{ml}$ dimethyl sulfoxide, $1 \mathrm{mM}$ each of all four deoxynucleotides, $0.2 \mathrm{mM}$ each of the primers, 2.5 units Taq polymerase (PerkinElmer Cetus, USA) and $200 \mathrm{ng}$ template. Samples were heated at $94^{\circ} \mathrm{C}$ for $5 \mathrm{~min}$ and at $57^{\circ} \mathrm{C}$ for $1 \mathrm{~min}$ in the first round of denaturation-annealing, followed by 40 cycles of 30 seconds at $94^{\circ} \mathrm{C}, 30$ seconds at $57^{\circ} \mathrm{C}$, and 30 seconds at $72^{\circ} \mathrm{C}$, and a final elongation for $7 \mathrm{~min}$ at $72^{\circ} \mathrm{C}$ in a Perkin-Elmer 9600 thermal cycler.

The Gs $\alpha$ mutations at codons 201 and 227 were screened by denaturating gradient gel electrophoresis (DGGE) analysis using chemical clamps instead of guanine-cytosine tails (15). Computer programs kindly provided by Lerman and colleagues were used to predict the melting behaviour of the fragments and to determine the appropriate denaturant concentration range. An aliquot (1/10) of the amplified product was clamped by ultraviolet irradiation $(365 \mathrm{~nm})$ and loaded on a $6 \%$ polyacrylamide gel with a linearly parallel gradient of $30-60 \%$ denaturant and electrophoresed at $160 \mathrm{~V}(80 \mathrm{~mA})$ for 7 hours for exon 8. The fragment spanning exon 9 was separated by electrophoresis for 7 hours at $160 \mathrm{~V}$ in a gradient containing $50-80 \%$ denaturant.

The amplified PCR products were purified on a microcon-100 column (Amicon, USA) and sequenced. For this, $10 \mathrm{ng}$ purified DNA was mixed with $5 \mathrm{pmol}$ primer in the ABI PRISM dRhodamine Dye terminator cycle sequencing kit (Perkin Elmer/Applied Biosystems, USA). The cycle sequencing conditions were $93^{\circ} \mathrm{C}$ for $3 \mathrm{~min}$, followed by 25 cycles of $94^{\circ} \mathrm{C}$ for 30 seconds, $55^{\circ} \mathrm{C}$ for 5 seconds, and $60^{\circ} \mathrm{C}$ for $4 \mathrm{~min}$. The fluorescent products were analysed on an ABI 377 machine.

\section{Results}

INITIAL PRESENTATION

Six of the seven girls presented with early vaginal bleeding. Breast development to stages B2 or B3 was recent in all of them and lasted for only a few weeks. Four girls had pubic hair (P2 or P3). The growth rate during the previous year was above normal in five patients, but their bone ages were all normal (table 1). None of the patients showed any of the pigmented skin lesions or bone dysplasia characteristic of McCune-Albright syndrome.

Plasma oestradiol concentration was raised $(30-270 \mathrm{pg} / \mathrm{ml})$ in five patients, but was within

Table 2 Acute ovarian follicular cyst: ultrasound and hormonal data at diagnosis

\begin{tabular}{lllll}
\hline & & \multicolumn{2}{l}{ Plasma } & \\
\cline { 3 - 5 } Case & $\begin{array}{l}\text { Ultrasound } \\
\text { ovarian cyst } \\
(\mathrm{mm})\end{array}$ & $\mathrm{E2}(\mathrm{pg} / \mathrm{ml})$ & $\begin{array}{l}F S H^{\star} \\
(\mathrm{mIU} / \mathrm{m}) l\end{array}$ & $\begin{array}{l}\text { LH* } \\
(\mathrm{mIU} / \mathrm{ml})\end{array}$ \\
\hline 1 & 65 & 43 & $<0.2 /<0.2$ & $<0.2 /<0.2$ \\
2 & 40 & 40 & $<0.2 / 0.6$ & $<0.2 /<0.2$ \\
3 & 30 & 270 & $0.2 / 0.4$ & $0.2 / 0.4$ \\
4 & 25 & 30 & $0.2 / 0.7$ & $0.2 / 0.2$ \\
5 & 50 & 5 & $0.5 / 0.5$ & $0.3 / 0.9$ \\
6 & 15 & 10 & $0.2 / 2$ & $0.2 / 0.7$ \\
7 & 46 & 125 & $0.2 / 0.9$ & $0.2 / 0.3$ \\
\hline
\end{tabular}

^Basal/LHRH peak response.

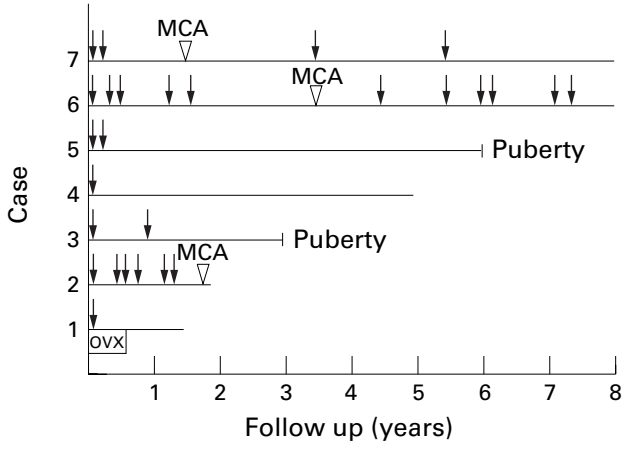

Figure 1 Follow up of patients with initial isolated gonadotropin independent ovarian activation. Arrows indicate recurrent episodes. MCA, McCune-Albright syndrome; OVX, ovariectomy.

the normal prepubertal range $(<15 \mathrm{pg} / \mathrm{ml})$ in two (patients 5 and 6). There were no plasma FSH and LH responses to LHRH stimulation in any of the girls, including those with prepubertal plasma oestradiol concentrations.

Pelvic ultrasound examination revealed unilateral ovarian cysts of $25-65 \mathrm{~mm}$ in six patients. Patient 6 was found to have a $15 \mathrm{~mm}$ diameter cyst only at the second episode of vaginal bleeding six months later (table 2 ). The contralaterals were 9-22 mm (upper limit for normal prepubertal ovary $25 \mathrm{~mm}$ ), suggesting a lack of gonadotropin stimulation. All patients had a stimulated uterus over $35 \mathrm{~mm}$ long.

\section{FOLLOW UP}

Follow up is shown in fig 1.

The clinical signs caused by oestrogen activity and the ultrasound evidence of ovarian cyst regressed within 2-4 weeks, except in patient 1. The ovarian cyst in this patient persisted and increased in size to $90 \mathrm{~mm}$. Her symptoms were unusually severe as her ovarian activity remained sustained with raised plasma oestradiol concentrations for seven months. Therefore a unilateral oophorectomy was performed. This was followed by regression of the clinical oestrogen activity and normalisation of the response to LHRH. Further follow up was not possible. Patient 2 was followed for 18 months, during which time she had five more episodes of oestrogenic activity. Patients 3 and 5 were followed for three and six years, respectively, with only one recurrent episode, and have now entered normal puberty. Patient 4 had no recurrence during a five year follow up. Patients 6 and 7 were followed for eight years and had multiple episodes of ovarian activation. McCune-Albright syndrome was diagnosed in patients 2,6 , and 7 at 18,15 , and 40 months, respectively, after the initial vaginal bleeding. This diagnosis was based on the development of bone dysplasia detected by repeated skeletal radiographs, as there were no characteristic skin lesions. These patients had numerous (4-11) recurrent episodes of bleeding which were more frequent than in patients 3,4 , and 5, who had long, uneventful follow up periods. They also were among the youngest patients. 

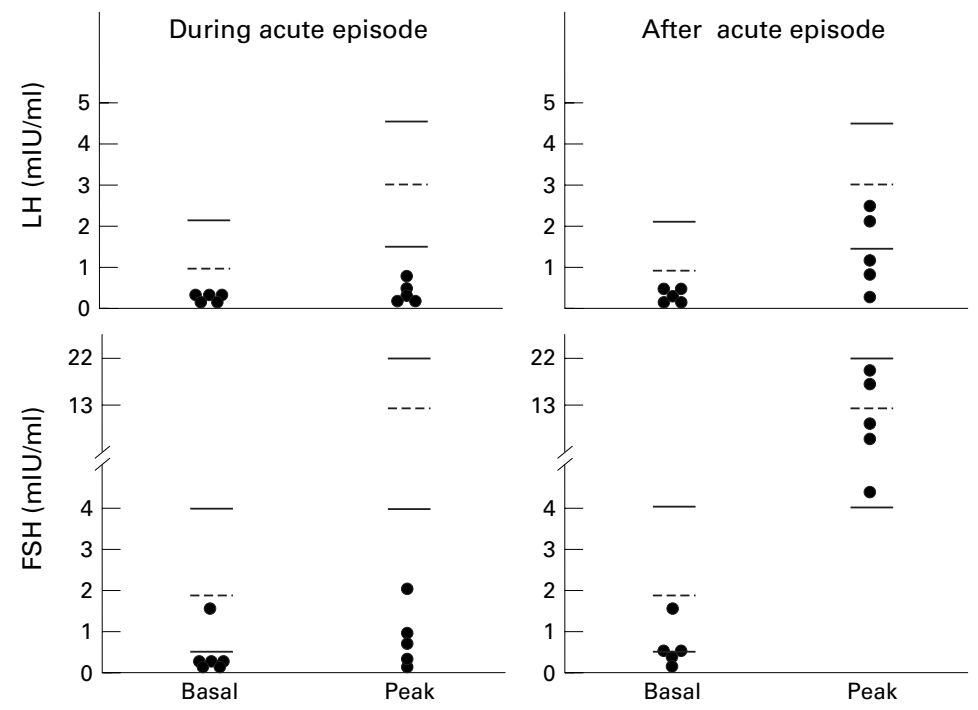

Figure 2 Plasma LH and FSH response to LHRH stimulation test during and after the initial acute episode of ovarian activation (mean and range of prepubertal control values).

HORMONAL CHANGES AFTER THE INITIAL ACUTE EPISODE

Of the five patients retested by LHRH stimulation 4-6 months after the initial acute episode (patients $1,2,4,6$, and 7 ), three still had a suppressed LH response (patients 2, 6, and 7) (fig 2 ), while the FSH response had returned to normal. These three patients later developed signs of McCune-Albright syndrome. All five patients also had undetectable $(<10 \mathrm{pg} / \mathrm{ml}$ ) plasma oestradiol concentrations and no clinical signs of high oestrogen.

\section{G PROTEIN MUTATIONS}

The DGGE method was used to identify PCR fragments with an aberrant migration pattern, indicating a potential mutation. These fragments were sequenced by direct automated sequencing. There was a $\mathrm{C}$ to $\mathrm{T}$ mutation at codon 201, causing an R201C missense mutation. This segregates with the McCune-Albright phenotype. Of the three patients investigatedpatients 1 (isolated ovarian cysts), 2, and 6 (both with evidence of McCune-Albright syndrome) - only patient 6 (bone tissue) had the mutation. Samples of ovarian tissue (patient 1) and blood leucocytes (patients 1,2, and 3) were negative. Patient 6 also had the most severe form of recurrent ovarian activation, with extensive bone dysplasia.

\section{Discussion}

The development of autonomous functional ovarian follicular cysts results in pseudoprecocious puberty. ${ }^{16}$ This report describes the initial presentation and the long term follow up of seven prepubertal girls who presented with isolated signs of sexual precocity-transient breast development and vaginal bleeding, sometimes accompanied by abdominal pain and large ovarian cysts detected by ultrasound. Spontaneous remission generally occurred, but there were often further episodes of ovarian activation and cyst formation with similar clinical features. The endocrine findings indicated autonomous ovarian activity with greatly increased plasma oestradiol concentrations during the early phase of central precocious puberty, together with low plasma LH and FSH basal and peak response to LHRH stimulation. However, the plasma oestradiol measurement may be misleading, since two girls had prepubertal plasma oestradiol values in spite of clinical evidence of increased oestrogen activity. These results contrasted with the complete suppression of gonadotropin response to LHRH stimulation. The apparent discrepancy between these results may be caused by variations in the plasma oestradiol concentrations, as suggested by the persistence of oestrogen stimulated cells in the vaginal smear. ${ }^{16}$ This type of finding should therefore be taken as strong evidence against central precocious puberty. It shows the need for an early LHRH stimulation test in patients whose clinical profile suggests autonomous ovarian activation.

Ovarian ultrasonography performed at the time of the initial episode is critical for diagnosis, as the presence of an ovarian cyst $\geqslant 9 \mathrm{~mm}$ in diameter is a strong indicator of pseudosexual precocity with autonomous ovarian activation. A study of 32 girls under eight years old found that 23 had true isosexual precocity, with $69 \%$ having small cysts less than $9 \mathrm{~mm}$ in diameter, and one with a larger cyst $(15 \mathrm{~mm})$. In contrast, the four patients with pseudosexual precocity had unilateral ovarian cysts with diameters of 15-64 mm. The lack of contralateral ovarian enlargement was also considered to indicate pseudosexual precocity with autonomous ovarian activation. ${ }^{12}$

Our patients were initially referred to us because of recent evidence of acute sexual precocity. Although surgery was necessary because of ovarian torsion in one case, conservative follow up should be possible for most of these patients, providing ultrasound monitoring is included.

Three patients showed evidence of McCuneAlbright syndrome. As described, they showed sexual precocity before the development of bone lesions and skin café au lait pigmentation. ${ }^{17}$ Although multiple episodes of vaginal bleeding and breast stimulation occurred before McCune-Albright syndrome was diagnosed, the frequency, number, and characteristics of such episodes did not appear to be specific or predictive of the outcome. However, the symptoms of two patients ( 2 and 6 ) were most severe. Therefore, a process self limited to the ovary could not be ascertained in any of these patients during their initial follow up. The LH response to LHRH stimulation remained suppressed several months after the initial episode, although the clinical evidence of oestrogen activity had disappeared in the three patients who developed McCune-Albright syndrome. Whether this is a characteristic feature of more severe and extensive cases remains to be evaluated in larger series of patients. Diagnosis of McCune-Albright syndrome requires a prolonged clinical follow up with repeated skeletal radiographs. ${ }^{18}$

The molecular basis of McCune-Albright syndrome is a mutation in the $\alpha$ subunit of the 
G protein, which couples cell surface receptors to the stimulation of adenyl cyclase, $\mathrm{G}_{\mathrm{s}} \alpha$. These mutations lead to the constitutive activation of adenyl cyclase in various tissues, including the ovary. ${ }^{19}$ A previous study showed that specific regions of abnormal ovarian tissue contained a higher proportion of mutant cells, by hybridisation of DNA with a mutant oligonucleotide probe. ${ }^{8}$ These results indicated a correlation of the abundance of mutant alleles with the pathological abnormalities in ovarian tissue. However, no such mutations were found in blood cells, dysplastic bone, or the café au lait spots of several patients. ${ }^{8}$ There were no mutations in the blood cells of our three affected patients, even in the patient with documented McCune-Albright syndrome.

Laboratory tests therefore have limitations, perhaps because of technical difficulties or the great variations in distribution and density of $\mathrm{G}_{\mathrm{s}} \alpha$ mutations within and between tissues. Hence only positive results should be considered as informative for clinical purposes. An arginine 201 to cysteine mutation of the $G_{s} \alpha$ protein was found in bone tissue, but not in any other tissues. This mutation causes a notable decrease in intrinsic GTPase activity, prolonging the lifetime of the active conformation.

We conclude that premature, intermittent ovarian activity mimicking precocious puberty may be caused by autonomous ovarian activation. The initial clinical and ultrasound picture is characteristic. A lack of plasma LH and FSH responses to LHRH, when the plasma oestrogen is normal prepubertal, is useful for diagnosing autonomous ovarian function. This episode may be a single event or there may be recurrences at unpredictable intervals, perhaps accompanied by other manifestations of the McCune-Albright syndrome. Sustained oestrogen activity rarely requires testolactone treatment. ${ }^{20}$ Ovarian surgery should be avoided, or should be very conservative in case of ovarian torsion. This is most important for follow up and treatment. Prepubertal girls are likely to present over several years of follow up with a continuous spectrum of clinical symptoms, from an isolated ovarian functional cyst to the full blown picture of McCune-Albright syndrome.
This study was supported by a fellowship from the Groupement Français de Gynecologie de l'Enfance et de l'adolescence (R-M KA).

1 Lyon A, De Bruyn R, Grant DB. Transient sexual precocity and ovarian cysts. Arch Dis Child 1985;60:819-22.

2 Benedict PH. Endocrine features in Albright's syndrome (fibrous dysplasia of bone). Metabolism 1962;11:30-45.

3 Richards GE, Kaplan SL, Grumbach MM. Sexual precocity caused by ovarian follicular cysts: spontaneous regression and recurrence with prepubertal gonadotropin levels. Pediatr Res 1977; 11:431.

4 Rieth KG, Comite F, Shawker TH, Cutler GB. Pituitary and ovarian abnormalities demonstrated by CT and ultrasound in children with features of the McCune-Albright syndrome. Radiology 1984;153:389-93.

5 Wierman ME, Beardsworth DE, Mansfield MJ, et al. Puberty without gonadotropins: a unique mechanism of sexual development. N Engl f Med 1985;312:65-72.

6 Case Records of the Massachusetts General Hospital (case 47, 1989). N Engl F Med 1989;321:1463-91.

7 Lee PA, Van Dop C, Migeon CJ. McCune-Albright syndrome: long term follow-up. $\mathcal{F} A M A$ 1986;256:2980-4.

8 Weinstein LS, Shenker A, Gejman PV, Merino MJ, Friedman E, Spiegel AM. Activating mutations of the stimulatory $\mathrm{G}$ protein in the McCune-Albright syndrome. N Engl f Med 1991;325:1688-95.

9 Tanner JM, Whitehouse RH. Clinical longitudinal standards for height, weight, height velocity, weight velocity and stages of puberty. Arch Dis Child 1976;51:170-9.

10 Sempe M, Pedron G, Roy MP. Auxologie, méthodes et séquences. Paris: Theraplix Publishers, 1979.

11 Greulich WW, Pyle SI. Radiographic atlas of skeletal developement of the hand and the wrist, 2nd ed. Stanford: Stanford Press, 1959.

12 King LR, Siegel MJ, Solomon AL. Usefulness of ovarian volume and cysts in female isosexual precocious puberty. $\mathcal{F}$ Ultrasound Med 1993;12:577-81.

13 Adan L, Souberbielle JC, Zucker JM, Pierre-Kahn A, Kalifa C, Brauner R. Adult height in 24 patients treated for growth hormone deficiency and early puberty. $\mathcal{F}$ Clin Endocrinol Metab 1997;82:229-33.

14 Fiet J, Gosling JP, Soliman H, et al. Hirsutism and acne in women: coordinated radioimmunoassays for eight relevant plasma steroids. Clinical Chemistry 1994;40:2296-305

15 Fernandez E, Bienvenu T, Desclaux-Arramond F, Beljord $\mathrm{K}$, Kaplan JC, Beldjord C. The use of chemical clamps in denaturing gradient gel electrophoresis: application in the detection of the most frequent Mediterranean $\beta$ thalassemic mutations. PCR Methods and Applications 1993;3: $122-4$.

16 Sinnecker G, Willig RP, Stahnke N, Braendle W. Precocious pseudopuberty associated with multiple ovarian follicular cysts and low plasma oestradiol concentrations. Eur 7 Pediatr 1989;148:600-2.

17 Mauras N, Blizzard RM. The McCune-Albright syndrome. Acta Endocrinology (Copenhagen) 1986;279(suppl):207-17.

18 Frisch LS, Copeland KC, Boepple PA. Recurrent ovarian cysts in childhood: diagnosis of McCune-Albright syndrome by bone scan. Pediatrics 1992;90:102-4.

19 Schwindinger WF, Levine MA. McCune-Albright syndrome. Trends in Endocrinology and Metabolism 1993;4:23842 .

20 Feuillan PP, Jones J, Cutler GB. Long term testolactone therapy for precocious puberty in girls with the McCuneAlbright syndrome. F Clin Endocrinol Metab 1993;77:64751. 